\title{
PENGEMBANGAN MODEL PEMBELAJARAN TEMATIK \\ SENI DAN BUDAYA MENGGUNAKAN VIDEO \\ TEATERIKALISASI COWONGAN \\ DI SEKOLAH DASAR
}

\author{
Anastasia Dwi Wiwik Indriati ${ }^{1}$, Kuntoro Kuntoro ${ }^{2}$, Akhmad Djazuli ${ }^{3}$ \\ ${ }^{1}$ SDN 4 Sokanegara, Purwokerto \\ ${ }^{2,3}$ Magister Pendidikan Dasar, Program Pascasarjana \\ Universitas Muhammadiyah Purwokerto \\ anastasiaselendangmerah@gmail.com; kuntoro@ump.ac.id; akhmadjazuli@ump.ac.id
}

\begin{abstract}
This study aims to develop a thematic learning model of art and culture using video theatericalization of "Cowongan" for students in elementary schools. This research is a research development that aims to improve the ability to verbalize "Kidung Kasengsaraan Mangsa Ketiga" with the Banyumas dialect. The research design uses $R$ and D Data collection techniques in research gather information, product design, product validation, product testing, design revision, trial use, product revision, mass production, and dissemination. These data sources are interviews, observations, taking questionnaires, and tests. The sampling technique uses cluster sampling as the population of SDN 4 Sokanegara students. The results of research in verbalizing the geguritan include laval, intonation, placement of pauses, and expressions. The observations of researchers obtained data that the average posttest results that the experimental class reached $90 \%$ of the expected score, while the average control class reached $75.75 \%$ of the expected score. The results of the effectiveness test in the research prove that the class that uses the product is better than the one that does not use the product so that the ability to speak up using the Banyumas dialect is more effective.
\end{abstract}

Keywords: Cowongan, Banyumas dialect, geguritan, elementary students

Abstrak: Penelitian ini bertujuan untuk mengembangkan sebuah model pembelajaran tematik seni dan budaya menggunakan video teaterikalisasi cowongan bagi peserta didik di sekolah dasar. Desain penelitian menggunakan $\mathrm{R}$ and $\mathrm{D}$ dengan 10 langkah penelitian. Teknik pengumpulan data meliputi pengumpulan informasi, desain produk, validasi produk, ujicoba produk, revisi desain, ujicoba pemakaian, revisi produk, pembuatan masal, dan deseminasi. Sumber data yang ini yaitu wawancara, observasi, pengambilan angket, dan tes. Tehnik pengambilan sampel menggunakan cluster sampling sebagai populasi peserta didik SDN 4 Sokanegara. Hasil pengamatan menunjukkan bahwa rata-rata hasil posttest bahwa kelas eksperimen (90\%) lebih tinggi dibandingkan kelas kontrol (75,75\%). Kelas yang menggunakan media video teaterikalisasi cowongan lebih baik daripada yang tidak menggunakan media tersebut dalam kemampuan melisankan geguritan menggunakan dialek Banyumas.

Kata kunci:: Cowongan, Dialek Banyumasan, Geguritan, Siswa SD

\section{Latar Belakang Masalah}

Dalam Kurikulum 2013 (Kurtilas) semua guru harus memiliki kemampuan atau kompetensi dalam melakukan pengembangan kurikulum sesuai tujuan tanpa meninggalkan falsafah Negara. Guru harus mengikuti perkembangan ilmu pengetahuan dan informasi untuk menuju generasi Indonesia emas tahun 2045. Guru menerapkan pembelajaran abad 21 di sekolah formal, dengan menerapkan kemampuan 4C (Critical thinking, Communication, Collaboration, Creativity). Metode tematik ini 
mengintegrasikan kemampuan siswa dalam hal sikap (afektif), ketrampilan (psikomotorik), dan pengetahuan (kognitif).

Hasil pengamatan peneliti dan angket kebutuhan di SDN 4 Sokanegara, peserta didik masih kurang dalam hal ketrampilan melisankan geguritan Banyumasan menggunakan dialek bahasa Banyumas dikarenakan kurangnya media bahan ajar dan strategi guru dalam meningkatkan ketercapaian kompetensi tersebut. Berlatarbelakang dari kondisi tersebut maka perlu dibuat produk berupaa model pembelajaran yang inovatif yang dapat meningkatkan kemampuan melisankan geguritan Banyumasan dengan video teaterikalisasi Cowongan.

\section{Pembelajaran Tematik}

Pembelajaran tematik di Indonesia sudah mulai diberlakukan pada kurikulum 2006 yaitu pada Kurikulum Tingkat Satuan Pendidikan (KTSP) meskipun penerapannya belum maksimal. KTSP tahun 2006 bahwa pembelajaran tematik hanya diberlakukan pada kelas rendah yaitu kelas satu, dua, dan tiga pada jenjang Sekolah Dasar (SD). Berbeda dengan kurikulum 2013 yang memberlakukan pembelajaran tematik dari kelas rendah hingga kelas tinggi, yakni kelas satu sampai kelas enam SD meskipun di kelas tiga dan kelas enam pembelajaran tematik belum sepenuhnya diterapkan. Pembelajaran tematik lebih menekankan keterlibatan siswa dalam proses belajar aktif sehingga siswa dapat memperoleh pengetahuan yang dipelajarinya.

\section{Seni Cowongan}

Salah satu cara membangun karakter bangsa dengan mentranformasi nilai-nilai budaya yaitu budaya hormat dan tanggung jawab pada seni Cowongan. Seni cowongan membangun karakter hormat yakni hormat terhadap diri sendiri, hormat terhadap orang lain dan hormat terhadap semua bentuk kehidupan dan lingkungan yang saling menjaga satu sama lain.

Tanggung jawab merupakan bentuk lanjutan dari rasa hormat. Jika kita menghormati diri sendiri dan orang lain maka kita merasakan sebuah ukuran dari tanggung jawab untuk menghormati kesejahteraan hidup (Likcona,2012 : 72).

Dalam seni cowongan yang merupakan tradisi masyarakat Banyumas yang agraris, sangat menghargai dan hormat terhadap alam. Tanggung jawab terhadap alam yang diciptakan Tuhan dengan melaksanakan pekerjaan bertani dengan sepenuh hati.

Masyarakat Banyumas pada jaman dahulu belum mengenal agama maka mereka mempercayaai kekuatan alam untuk mendatangkan hujan dengan sarana boneka siwur yang dicemongcemong sebagai ujud Dewi Sri, Dewi Kemakmuran yang mendatangkan hujan tatkala kemarau panjang. Ungkapan permohonan mereka kepada semesta diungkapkan melalui tradisi Cowongan.

Pembangunan karakter hormat dan tanggungjawab dapat tercermin dalam seni cowongan karena berhubungan dengan proses menjaga lingkungan alam agar tidak tandus dan selalu subur. Nilai-nilai luhur hormat dan tanggung jawab dijiwai oleh nilai-nilai Pancasila dan UUD 45 terinternalisasi dalam diri individu dan warga Negara yang bertanggungjawab yang didasari oleh iman dan takwa kepada Tuhan Yang Maha Esa.

\section{Geguritan}

Tradisi Jawa mengenal wacana sastra yang menggunakan bahasa padat, pekat, dan memiliki makna yaitu Geguritan (Puisi Jawa). Geguritan merupakan cipta sastra terbaru yang hidup hingga kini dan tidak memiliki kebakuan puitik. Geguritan berasal dari kata dasar gurit yang berarti Kidung atau tulisan yang berujud tatahan. Geguritan dibagai 
menjadi dua yaitu : Geguritan Gagrag lawas(tradisional) dengan ketentuan :terdiri dari 4-8 baris, jumlah suku kata tiap larik sama, jatuhnya suara tiap akhir kalimat sama, dimulai dengan kata "sun Nggegurit." Geguritan Gagrag Anyar disebut puisi Jawa modern lebih mengutamakan pada pilihan kata yang berisi (Diksi),gaya bahasa (Purwakanthi, Dwi Purwa, Dwiwasana,seselan ), Irama. Membaca geguritan diperlukan gaya agar menimbulkan efek keindahan.

\section{Prosedur Penelitian}

1. Desain Awal Produk

Produk yang dihasilkan dalam penelitian dan pengembangan ini berupa 2 buah video dan 2 buah buku panduan tematik. Video tersebut berupa pembelajaran tematik seni dan budaya dan video pertunjukkan teataterikalisasi cowongan. Buku yang dibuat adalah Buku Tematik Siswa dan Buku Tematik Guru.

2. Perbaikan Desain

Desain awal produk yang telah dibuat peneliti dimintakan persetujuan kepada pembimbing. Pembimbing memberi beberapa masukan untuk memperbaiki desain produk. Peneliti mendesain ulang produk awal sesuai masukan dari dosen pembimbing.

3. Validasi Desain

Desain produk yang terdiri dari beberapa prototipe mengalami tahap demi tahap perubahan untuk menjadi produk yang lebih baik. Desain tersebut kemudian divaliadasi oleh ahli materi. Validasi desain produk juga dilakukan oleh guruguru kelas 1, 2, 3, 4, 6, dan guru mapel Budaya Banyumas. Validasi produk oleh guru meliputi (a) kesesuaian indicator dengan KD dan SK. ( b) Kesesuaian RPP dengan KD dan SK, (c) Kesesuaian materi ajar dengan $\mathrm{KD}$ dan $\mathrm{SK}$, (d) Keseuaian bahan ajar buku panduan siswa dan buku panduan guru dengan $\mathrm{KD}$, (e) Kesesuaian lembar kerja siswa dengan $\mathrm{KD}$, (f) kesesuaian alat evaluasi dan penilaian, (g) ketepatan cakupan materi, (h) kedalaman materi, kemenarikan materi,(j) keterlibatan siswa dalam aktivitas belajar, (k) kualitas penyajian materi, (l) tampilan kaset ved yang berwarna-warni, (m) tampilan kaset ved yang bergambar pertunjukkan Cowongan, (n) tampilan wadah ved berwarna biru, (o) adanya teks teaterikalisasi Cowongan, (p) adanya teks sinopsi Cowongan, (q)adanya penulisan sub title, (r) kesesuaian suara dengan music.

4. Ujicoba terbatas

Uji coba tahap awal dilakukan pada kelompok yang terbatas. Pengujian dilakukan dengan tujuan untuk mendapatkan informasi apakah produk ini lebih efektif dan efisien dibandingkan dengan tidak menggunakan produk (tanpa media pembelajaran). Pengujian dapat dilakukan dengan eksperimen yaitu membandingkan efektifitas pembelajaran menggunakan produk pembelajaran dan yang tanpa produk pembelajaran. Efektifitas produk akan diukur melalui pencapaian meningkatnya kemampuan melisankan geguritan dengan dialek Banyumasan sesuai lafal, intonasi, penempatan jeda dan ekspresi yang tepat.

5. Revisi Produk

Pengujian produk pada sampel yang terbatas menunjukkan bahwa pembelajaran tematik seni budaya menggunakan produk yaitu video teaterikalisasi Cowongan lebih baik dari pembelajaran yang tidak menggunakan produk. Kelemahan dari produk itu adalah pada penilaian lafal (pengucapan). Peneliti merevisi produk kembali agar mendapatkan produk yang lebih baik sehingga meningkatkan ketercapaian tujuan pembelajaran yakni melisankan geguritan dengan dialek Banyumasan dengan intonasi, lafal, penempatan jeda, dan ekspresi yang tepat.

6. Ujicoba Efektifitas Produk

Peneliti melakukan ujicoba pemakaian produk kepada skala yang lebih luas. Peneliti mengadakan ujicoba produk terhadap 26 peserta didik kelas 4 SDN 4 
Sokanegara yang dibagi dalam dua kelompok yaitu kelompok eksperimen dan kelompok control. Kelompok eksperimen adalah kelompok yang dikenai tindakan (pembelajaran menggunakan produk) dan kelompok control adalah kelompok yang tidak menggunakan produk.

Ujicoba produk menggunakan model eksperimen ditunjukkan pada Gambar 1.
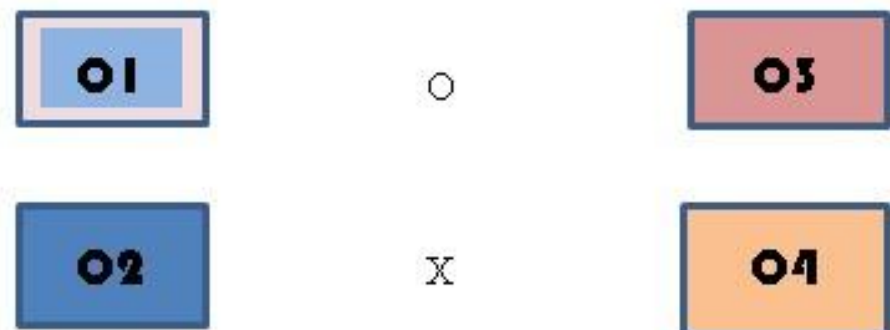

$\mathrm{X}$

04

Gambar 1. Desain eksperimen dengan kelompok control.
Keterangan
O1 = Nilai kemampuan awal kelompok eksperimen
$\mathrm{O} 2$ = nilai kemampuan awal kelompok control
$\mathrm{O} 3$ = nilai kelompok eksperimen tanpa menggunakan produk
$\mathrm{O} 4=$ nilai kelompok control setelah menggunakan produk

7. Penyempurnaan Produk

Beberapa hal yang disempurnakan oleh peneliti adalah pada video model pembelajaran tematik dengan memberikan ilustrasi musik di sela sela video model pembelajaran dan menuliskan nama peneliti, dosen pembimbing 1 , dosen pembimbing 2, dan ahli materi dalam video pembelajaran tematik. Buku Panduan Siswa dan Buku Pand Peneliti juga mengembangkan penelitian dengan melihat respon siswa terhadap produk peneliti. Respon siswa secara individu diperoleh dengan cara menghitung hasil respon siswa terhadap produk peneliti kemudian uan Guru disempurnakan dengan menuliskan nama peneliti, dosen pembimbing 1 , dan dosen pembimbing 2 pada halaman sampul dalam buku. Halaman buku bagian belakang diberi halaman Catatan.

8. Produk Untuk Diseminasi

Deseminasi dilaksanakan di KKG Gugus Sokawiyata dengan dihadiri oleh
Pengawas dari Koordinator Wilayah Kecamatan Dinas Pendidikan Purwokerto Timur.

Peneliti juga mengembangkan penelitian dengan melihat respon siswa terhadap produk peneliti. Respon siswa secara individu diperoleh dengan cara menghitung hasil respon siswa terhadap produk peneliti kemudian

\section{HASIL DAN PEMBAHASAN}

\section{Validasi Desain}

Desain produk yang sudah dianggap layak untuk diujicoba kemudian di validasi oleh ahli materi, Dr. Wakhudin, M.Pd, wakil ketua Ganasetra (Lembaga Pengembangan Seni tradisional Nusantara). Adapun hasil validasi disajikan pada Tabel 1.Disamping itu validasi dilakukan oleh Guru. Adapun hasil validasi desain yang dilakukan oleh Guru Kelas dan Guru Mapel Budaya Banyumasan ditampilkan pada Tabel 2. 
Tabel 4.1 Hasil Validasi Produk Dilihat dari Aspek Materi dan Aspek Tampilan Untuk Ahli Materi

\begin{tabular}{|c|c|c|c|c|c|c|c|c|}
\hline No & Aspek yang dinilai & & \multicolumn{4}{|c|}{ Penilaian } & $\mathrm{P} \%$ & Ket \\
\hline & Aspek materi & 1 & 2 & 3 & 4 & 5 & & \\
\hline 1 & $\begin{array}{l}\text { Kesesuaian indikator dengan } \\
\text { KD dan SK }\end{array}$ & & & & V & & 80 & Valid \\
\hline 2 & $\begin{array}{lll}\text { Kesesuaian } & \text { RPP } & \text { dengan } \\
\text { KD,Sk } & & \\
\end{array}$ & & & & & $\mathrm{V}$ & 100 & Sangat valid \\
\hline 3 & $\begin{array}{l}\text { Kesesuaian materi ajar dengan } \\
\text { KD,SK }\end{array}$ & & & & $\mathrm{V}$ & & 80 & Valid \\
\hline 4 & $\begin{array}{l}\text { Kesesuaian bahan ajar buku } \\
\text { panduan siswa dan panduan } \\
\text { guru dengan KD }\end{array}$ & & & & & $\mathrm{V}$ & 100 & sangat valid \\
\hline 5 & $\begin{array}{l}\text { Kesesuaian Lembar kerja } \\
\text { Siswa dengan KD }\end{array}$ & & & & V & & 80 & Valid \\
\hline 6 & $\begin{array}{l}\text { Kesesuaian alat evaluasi dan } \\
\text { penilaian }\end{array}$ & & & & $\mathrm{V}$ & & 80 & Valid \\
\hline 7 & Ketepatan cakupan materi & & & & & & & \\
\hline 8 & Kedlaman materi & & & & $\mathrm{V}$ & & 80 & Valid \\
\hline 9 & Kemenarikan materi & & & & V & & 80 & Valid \\
\hline 10 & $\begin{array}{l}\text { Keterlibatan siswa dalam } \\
\text { aktivitas belajar }\end{array}$ & & & & & $\mathrm{V}$ & 100 & Sangat valid \\
\hline 11 & Kualitas penyajian materi & & & & V & & 80 & Valid \\
\hline & Aspek tampilan & & & & & & & \\
\hline 12 & $\begin{array}{l}\text { Tampilan kaset vcd yang } \\
\text { berwarna warni }\end{array}$ & & & & $\mathrm{V}$ & & 80 & Valid \\
\hline 13 & $\begin{array}{lrr}\begin{array}{l}\text { Tampilan } \\
\text { bergambar }\end{array} & \text { ved yang } \\
\text { cowongan } & & \text { pertunjukan }\end{array}$ & & & & & V & 100 & Sangat valid \\
\hline 14 & $\begin{array}{l}\text { Tampilan wadah ved berwarna } \\
\text { biru }\end{array}$ & & & & $\mathrm{V}$ & & 80 & Valid \\
\hline 15 & $\begin{array}{l}\text { Adanya teks teaterikalisasi } \\
\text { cowongan dengan huruf arial } \\
\text { narrow berwarna hitam dan } \\
\text { kertas biru }\end{array}$ & & & & V & & 80 & Valid \\
\hline 16 & $\begin{array}{l}\text { Adanya teks synopsis } \\
\text { cowongan dengan huruf times } \\
\text { new roman berwarna hitam } \\
\text { dan kertas biru }\end{array}$ & & & & $\mathrm{V}$ & & 80 & Valid \\
\hline 17 & $\begin{array}{l}\text { Adanya penulisan subtitle } \\
\text { dengan huruf warna putih pada } \\
\text { video teaterikalisasi cowongan }\end{array}$ & & & & V & & 80 & Valid \\
\hline 18 & Kesesuaian suara dan music & & & & V & & 80 & Valid \\
\hline & Rata-rata & & & & & & 84,4 & \\
\hline
\end{tabular}

Setelah dikonversi dengan skala 5, kualifikasi tingkat kevalidan yang telah diujicobakan ialah $84,4 \%$ sehingga hasil kevalidan termasuk kualifikasi valid dan tidak direvisi 
Tabel 2. Hasil Validasi dari guru kelas 1,2,3, 4, 6 dan Guru Mapel Budaya Banyumas

\begin{tabular}{|c|c|c|c|c|c|}
\hline $\begin{array}{c}\text { Hasil } \\
\text { persentase } \\
\text { validasi } \\
\text { guru kelas } \\
1\end{array}$ & $\begin{array}{c}\text { Hasil } \\
\text { persentase } \\
\text { validasi } \\
\text { guru kelas } \\
2\end{array}$ & $\begin{array}{c}\text { Hasil } \\
\text { persentase } \\
\text { validasi } \\
\text { guru kelas } \\
3\end{array}$ & $\begin{array}{c}\text { Hasil } \\
\text { persentase } \\
\text { validasi } \\
\text { guru kelas } \\
4\end{array}$ & $\begin{array}{c}\text { Hasil } \\
\text { persentase } \\
\text { validasi } \\
\text { guru kelas } \\
6\end{array}$ & $\begin{array}{c}\text { Hasil } \\
\text { persentase } \\
\text { validasi } \\
\text { guru mapel } \\
\text { Budaya } \\
\text { banyumas }\end{array}$ \\
\hline $100 \%$ & $95,2 \%$ & $100 \%$ & $93,3 \%$ & $90,6 \%$ & $100 \%$ \\
\hline
\end{tabular}

Tabel 2 menunjukkan hasil validasi yang dilakukan oleh Guru Kelas dan Guru Mapel Budaya Banyumasan. Tabel tersebut mengindikasikan bahwa media Cowongan adalah valid untuk digunakan..

\section{Ujicoba Produk}

Pengujian dilakukan dengan tujuan untuk mendapatkan informasi apakah produk ini lebih efektif dan efisien dibandingkan dengan tidak menggunakan produk (tanpa media pembelajaran). Pengujian dapat dilakukan dengan eksperimen yaitu membandingkan efektifitas pembelajaran menggunakan produk pembelajaran dan yang tanpa produk pembelajaran. Efektifitas produk akan diukur melalui pencapaian meningkatnya kemampuan melisankan geguritan dengan dialek Banyumasan sesuai lafal, intonasi, penempatan jeda dan ekspresi yang tepat. Hasil ujicoba produk terbatas ditampilkan pada Tabel 3 dan 4.

Tabel 3. Hasil Uji Coba Produk Sebelum menggunakan Produk

\begin{tabular}{|c|c|c|c|c|c|c|}
\hline No & Responden & Pelafalan & intonasi & $\begin{array}{c}\text { Penempatan } \\
\text { jeda }\end{array}$ & Ekspresi & Jumlah \\
\hline 1 & A1 & 2 & 3 & 3 & 3 & 11 \\
\hline 2 & A2 & 2 & 1 & 2 & 2 & 7 \\
\hline 3 & A3 & 2 & 2 & 2 & 2 & 8 \\
\hline 4 & A4 & 1 & 2 & 2 & 2 & 7 \\
\hline 5 & A5 & 2 & 3 & 4 & 2 & 10 \\
\hline 6 & A6 & 1 & 2 & 2 & 2 & 7 \\
\hline Jumlah & & 10 & 13 & 14 & 13 & 50 \\
\hline
\end{tabular}

Tabel 4. Hasil ujicoba Setelah menggunakan Produk

\begin{tabular}{|c|c|c|c|c|c|c|}
\hline No & Responden & Lafal & Intonasi & $\begin{array}{c}\text { Penempatan } \\
\text { jeda }\end{array}$ & ekspresi & Jumlah \\
\hline 1 & A1 & 3 & 4 & 4 & 4 & 15 \\
\hline 2 & A2 & 3 & 2 & 3 & 3 & 11 \\
\hline 3 & A3 & 3 & 3 & 3 & 3 & 12 \\
\hline 4 & A4 & 2 & 3 & 3 & 3 & 11 \\
\hline 5 & A5 & 3 & 4 & 4 & 3 & 14 \\
\hline 6 & A6 & 2 & 3 & 3 & 3 & 11 \\
\hline & Jumlah & 16 & 19 & 20 & 19 & 74 \\
\hline
\end{tabular}

Tabel 3 dan 4 menunjukkan hasil uji coba terbatas untuk produk Pengujian produk pada sampel yang terbatas menunjukkan bahwa pembelajaran 
tematik seni budaya menggunakan produk yaitu video teaterikalisasi Cowongan lebih baik dari pembelajaran yang tidak menggunakan produk. Kelemahan dari produk itu adalah pada penilaian lafal (pengucapan). Peneliti merevisi produk kembali agar mendapatkan produk yang lebih baik sehingga meningkatkan ketercapaian tujuan pembelajaran yakni melisankan geguritan dengan dialek Banyumasan dengan intonasi, lafal, penempatan jeda, dan ekspresi yang tepat.

Setelah produk direvisi, dilanjutkan dengan ujicoba luas pada siswa Kelas 4 SDN Sokanegara. Siswa tersebut dibagi menjadi 2 kelompok yaitu kelompok eksperimen dan kelompok kontrol. Hasil posttest kedua kelompok ditampilkan pada Tabel 5.

Tabel 5. Perbandingan Hasil Postest Ujicoba Luas

\begin{tabular}{|c|c|c|}
\hline $\begin{array}{c}\text { Kelas control } \\
\text { (Tanpa menggunakan } \\
\text { produk })\end{array}$ & Aspek yang diukur & $\begin{array}{c}\text { Kelas eksperimen } \\
\text { (Menggunakan produk) }\end{array}$ \\
\hline $76 \%$ & Lafal & $92 \%$ \\
\hline $78 \%$ & Intonasi & $90 \%$ \\
\hline $82 \%$ & Penempatan jeda & $94 \%$ \\
\hline $67 \%$ & Ekspresi & $84 \%$ \\
\hline $75,75 \%$ & Rata-rata & $90 \%$ \\
\hline
\end{tabular}

Tabel 5 menunjukkan hasil posttest ujicoba luas. Hasil ini mengindikasikan bahwa pembelajaran menggunakan video teatrikalisasi Cowongan memberikan hasil yang lebih baik dalam melisankan geguritan
Banyumasan dalam hal lafal, intonasi, penempatan jeda dan ekspresi.

Terdapat beberapa perbaikan selam pengembangan produk. Perbaikan yang dilakukan ditampilkan pada Tabel 6.

Tabel 6. Tahap Pengembangan Produk

\begin{tabular}{|c|c|c|c|}
\hline No. & Desain awal & Perbaikan ke-1 & Perbaikan ke-2 \\
\hline 1 & $\begin{array}{l}\text { Cover dvd bagian depan dan } \\
\text { belakang dominansi diberi } \\
\text { gambar pertunjukkan cowongan } \\
\text { dan gambar pembelajaran } \\
\text { teaterikalisasi cowongan. Cover } \\
\text { tertulis Pengembangan Bahan } \\
\text { Ajar Budaya banyumas Seni } \\
\text { Cowongan }\end{array}$ & $\begin{array}{l}\text { Gambar tetap namun tulisan } \\
\text { yang diganti menjadi } \\
\text { Pengembangan } \\
\text { Pembelajaran } \\
\text { dan Bematik Seni } \\
\text { Video } \\
\text { Cowongan di Sekolah Dasar }\end{array}$ & $\begin{array}{l}\text { Tidak ada perbaikan sesuai } \\
\text { perbaikan ke }-1\end{array}$ \\
\hline 2 & $\begin{array}{l}\text { Penutup cd yang masih polos } \\
\text { ditempel dengan stiker bergambar } \\
\text { pertunjukkan cowongan }\end{array}$ & $\begin{array}{l}\text { Ada perbaikan gambar stiker } \\
\text { yaitu untuk cd pembelajaran } \\
\text { tematik } \\
\text { pembelajaran tematik di } \\
\text { kelas, sedangkan video } \\
\text { teaterikalisasi } \\
\text { masih tetap } \\
\text { gambar } \\
\text { cowowongangakan } \\
\text { cowongan }\end{array}$ & Tidak ada perbaikan \\
\hline 3 & $\begin{array}{l}\text { Buklet berisi informasi tentang } \\
\text { cerita cowongan, dan teks } \\
\text { teaterikalisai geguritan dengan } \\
\text { bahasa Banyumas }\end{array}$ & $\begin{array}{lr}\text { Ada penambahan buklet } \\
\text { yang semula berisi teks cerita } \\
\text { cowongan, dan teks } \\
\text { geguritan r berbahasa } \\
\text { Banyumas ditambahkan } \\
\text { dengan teks } & \text { terjemahan }\end{array}$ & $\begin{array}{l}\text { Tidak ada perbaikan sesuai } \\
\text { perbaikan ke }-1\end{array}$ \\
\hline
\end{tabular}




\begin{tabular}{|c|c|c|c|}
\hline & & $\begin{array}{l}\text { gegurutan menggunakan } \\
\text { Bahasa Indonesia. }\end{array}$ & \\
\hline 4 & $\begin{array}{l}\text { Cd video pembelajaran cowongan } \\
\text { berduarasi } 13 \text { menit } 29 \text { detik }\end{array}$ & $\begin{array}{l}\text { Tidak ada perbaikan sesuai } \\
\text { desain awal }\end{array}$ & $\begin{array}{lr}\text { Ada penambahan pada } \\
\text { videorikalisasi } \\
\text { cowongan diberi penulisan } \\
\text { sub title bahasa Banyumas, } \\
\text { ditulis berwarna putih. }\end{array}$ \\
\hline 5 & $\begin{array}{l}\text { Cd video pembelajaran tematik } \\
\text { seni dan budaya menayangkan } \\
\text { contoh membaca r teks } \\
\text { teaterikalisasi dan contoh gerak } \\
\text { asar tari cowongan dan ujungan }\end{array}$ & $\begin{array}{l}\text { Ada perbaikan } \begin{array}{r}\text { dengan } \\
\text { photting }\end{array} \\
\text { pengambilan } \\
\text { kembali. CD Pembelajaran } \\
\text { tematik menayangkan proses } \\
\text { pembelajaran dari awal } \\
\text { hingga akhir dan contoh } \\
\text { pembelajaran melisankan } \\
\text { geguritan dengan media } \\
\text { video pembelajaran } \\
\text { teaterikalisasi cowongan }\end{array}$ & $\begin{array}{lr}\text { Ada perbaikan } & \text { dengan } \\
\text { penambahan melengkapi } \\
\text { pengambilan } r \text { adegan } \\
\text { menyanyikan } r \text { lagu } \\
\text { Indonesia Raya yang } \\
\text { semula tidak ditayangkan } \\
\text { utuh kemudian diperbaiki } \\
\text { dengan penayangan utuh } \\
\text { menyanyikan } \\
\text { Indonesia Raya. lagu }\end{array}$ \\
\hline 6 & $\begin{array}{l}\text { Buku Tematik Siswa diberi } \\
\text { sampul warna ungu dengan } \\
\text { tulisan kuning dan putih. Buku } \\
\text { Panduan ini pada sampul depan } \\
\text { tertulis Buku Tematik Seni dan } \\
\text { Budaya Kurikulum } 13 \text { Kelas } 4 \\
\text { Sekolah Dasar. Tema } 1 \text { Seni dan } \\
\text { Budaya, Sub Tema } 1 \text { Indahnya } \\
\text { Keragaman Budaya di Daerahku. } \\
\text { Buku SiswaTematik kelas IV } \\
\text { SD/MI }\end{array}$ & $\begin{array}{l}\text { Ada Perbaikan cetak pada } \\
\text { buku tematik siswa karena } \\
\text { ada penulisan pada bagian } \\
\text { sampul depan yang tidak } \\
\text { menggunakan Kaidah EYD }\end{array}$ & $\begin{array}{l}\text { Ada perbaikan berupa } \\
\text { penambahan tulisan pada } \\
\text { sampul buku siswa yaitu } \\
\text { mencantumkan nama } \\
\text { penulis, dosen pembimbing } \\
1 \text {, dosen pembimbing } 2 \text {. }\end{array}$ \\
\hline 7 & $\begin{array}{l}\text { Buku tematik Panduan Guru lebih } \\
\text { tebal karena isinya menampilkan } \\
\text { Lembar evaluasi, dan Penilaian } \\
\text { serta RPP yang tidak ada dalam } \\
\text { buku Siswa. Buku diberi sampul } \\
\text { warna biru, tulisan putih. Tertulis } \\
\text { Buku Tematik Seni dan Budaya } \\
\text { Kurikulum } 13 \text { Kelas } 4 \text { Sekolah } \\
\text { Dasar. Tema } 1 \text { Seni dan Budaya, } \\
\text { Sub Tema } 1 \text { Indahnya Keragaman } \\
\text { Budaya di Daerahku. Buku Guru } \\
\text { Kelas IV SD/MI. }\end{array}$ & $\begin{array}{l}\text { Ada Perbaikan cetak pada } \\
\text { buku tematik guru karena } \\
\text { ada penulisan pada bagian } \\
\text { sampul depan yang tidak } \\
\text { menggunakan Kaidah EYD }\end{array}$ & $\begin{array}{l}\text { Ada perbaikan berupa } \\
\text { penambahan tulisan pada } \\
\text { sampul buku guruyaitu } \\
\text { mencantumkan nama } \\
\text { penulis, dosen pembimbing } \\
1 \text {, dosen pembimbing } 2 .\end{array}$ \\
\hline
\end{tabular}

\section{IV.Simpulan}

Kemampuan peserta didik dalam melisankan geguritan berbahasa Banyumas dapat ditingkatkan melalui pembelajaran tematik menggunakan video teaterikalisasi cowongan. Produk yang telah dikembangkan berupa $C D$ pembelajaran tematik seni dan budaya, CD video teaterikalisasi Cowongan, Buku Tematik Guru dan Siswa, dan Buku Tematik. Melalui produk tersebut, kemampuan Kompetensi Dasar berupa melisankan geguritan menggunakan Bahasa Banyumas yang sesuai dengan laval, intonasi, ekspresi dan penempatan jeda yang tepat dapat dicapai.

\section{Daftar Pustaka}

Amiruddin, 2011, Pengantar Apresiasi Karya Sastra . Bandung: Sinar Baru Algesindo Offset Bandung.

Direktorat Jenderal Guru dan Tenaga Kependidikan. (2016). Bahan Ajar PLPG Materi Keprofesionalan dan Pedagogik. Jakarta 
Departemen Pendidikan Nasional. (2008). Panduan Pengembangan Bahan Ajar. Jakarta: Direktorat Jenderal Manajemen Pendidikan Dasar dan Menengah.

Kementerian Pendidikan dan Kebudayaan. (2013). Bahasa Indonesia, Ekspresi Diri dan Akademik. Jakarta: Kementerian Pendidikan dan Kebudayaan.

Khoedri, M,. Banyumas Wisata dan Budaya.(1991).Brebes:.Bumiantik

Maryono, (2015). Analisa tari. Surakarta:ISI Press

Murgiyanto, Sal, (2004). Tradisi dan Inovasi. Beberapa Masalah Tari di Jakarta: Wedatama Widya Sastra.

Badan Pengembangan dan Pembinaan Bahasa Kementerian Pendidikan dan Kebudayaan. (2016), Antologi Cerita Anak berbasis Kearifan Lokal, Jakarta : Badan Pengembangan dan Pembinaan Bahasa Kementerian Pendidikan dan Kebudayaan.

Permendikbud No 67 tahun 2013, Kerangka Dasar Dan Struktur kurikulum SD/MI

Pusat Bahasa Departemen Pendidikan Nasional, 2008. Kamus Besar Bahasa Indonesia ,Jakarta : Balai Pustaka

Prastowo, A, 2012. Panduan Kreatif Membuat Bahan Ajar Inovatif. Yogyakarta: Diva Press

Sugiyono, (2006). Metode Penelitian Kuantitatif, Kualitatif, dan $R \& D$. Bandung: Alfabeta.
Sukiyadi,dkk, (2006). Kurikulum \& Pembelajaran . Bandung: UPI Press

Suyanto,dkk,2013. Menjadi Guru Profesional:Erlangga

Riantiarno, N.2011 Kitab Teater Tanya Jawab Seputar Seni Pertunjukkan: Grasindo

Tarigan, Guntur, 2008. Berbicara Sebagai Ketrampilan Berbicara. Bandung: Angkasa

UU NO 20 tahun 2003 tentang Sistem Pendidikan Nasional

Nugroho. Wisnu, 2017, Model Pembelajaran Dick and Carrey, Kajian Linguistik dan Sastra, V ol 1 no 2 Desember , 119-126

Nurdyansyah, \& Luly Riananda (2016), Developing ICT -BasedLearning Model to Improve Learning Outcomes IPA of SD Fish Market in Sidoarjo, Proceedings of International Research Clinic \& Scientific Publications of Educational Technology, Jurnal TEKPEN , 1 (2),929-930

Suwardi, 27-30 Juni 2005, Bengkel Sastra Jawa, http://staffnew.uny.ac.id/upload/131 872518pengabdian/c1bengkel.pdf 
